\title{
ENTROPY PREDICTION OF BENZENE DERIVATIVES USING TOPOLOGICAL INDICES
}

\author{
HOSSEIN HOSSEINI and FATEMEH SHAFIE| ${ }^{\text {** }}$
}

\begin{abstract}
In this study, a QSPR study relating topological indices to the entropy of 69 benzene derivatives is reported. The entropy values were calculated at HF level of theory (6-31 G basis sets) by Gussian 98.

Multiple linear regression (MLR) provided good models with three to seven independent variables. The best model obtained is based on three descriptors: Randić, Wiener and Szeged topological indices
\end{abstract}

Keywords: Topological indices; benzene derivatives; QSPR; MLR method.

\section{INTRODUCTION}

One of the most important purposes in application of mathematical and statistical methods is to find a relationship between molecular structure and values of physical properties, chemical reactivity or biological activity. As a result, quantitive structure-property relationship (QSPR) and quantitative structure-activity (QSAR) studies have been promoted.

Topological indices (Tls), as molecular descriptors, are important tools in QSPR/QSAR studies [1-11]. A topological index is a graph invariant number calculated from a graph representing a molecule.

The physicochemical properties of compounds are important in many fields, including pharmaceutics, chemistry, biochemistry and environmental sciences. Property estimations can help to minimize time and cost in producing new chemical materials with desired properties.

\footnotetext{
a Department of Chemistry, Science Faculty, Arak Branch, Islamic Azad University, Arak, Iran

*Corresponding author: f-shafiei@iau-arak.ac.ir
} 
Predictive methods for estimating thermodynamic properties, such as enthalpies of formation, Gibbs free energy and entropies of acyclic and aromatic compounds, on the basis of fundamental concepts on molecular structure have been reported [12].

Artificial Neural Networks were also used in developing QSPR models for prediction of physicochemical properties [13-16].

Prediction of entropies and enthalpies of organic compounds by using group contribution methods was also published [17-19]. Prediction of standard absolute entropy $\left(\mathrm{S}_{298} \mathrm{~K}\right)$ of gaseous organic and inorganic compounds was reported in [20,21].

In thermodynamics, entropy (usual symbol $\mathrm{S}$ ) is a measurement of the randomness or disorder of a system.

In the present work, we developed QSPR models for entropy estimation of benzene derivatives by describing the chemical structure by the aid of topological indices. Benzene derivatives are used in a wide range of technological applications.

Experimental data of benzene derivatives are often scarce, and at this point, topological descriptors provide powerful tools for modeling and extrapolating experimental data.

The main aim of this study is to illustrate the usefulness of topological indices in QSPR study of entropy (S) of benzene derivatives. As far as we are aware, this is the first QSPR study for prediction of benzene derivatives entropies using topological indices.

\section{METHODS}

The entropy(S) of 69 benzene derivatives (benzene included) was computed at the Hartree-Fock (HF) level of theory, using the ab initio 6-31G basis sets. The benzene derivatives in this set have seven different substituents, each substituent being present in at least six compounds. These substituents are amino, bromo, chloro, hydroxyl, methyl, methoxyl and nitro groups. Studied benzene derivatives and their entropy are listed in Table 1. To obtain an appropriate QSPR model we used multiple linear regression (MLR) procedure, by SPSS software, version 16, and backward stepwise regression was used to construct the QSPR models.

For drawing the graphs of our results, we used the Microsoft Office Excel - 2003 program. 
Table 1. Benzene derivatives and their entropy.

\begin{tabular}{|c|c|c|c|c|c|}
\hline Compounds & & $\begin{array}{c}\mathrm{S} \\
(\mathrm{J} / \mathrm{molK})\end{array}$ & Compounds & & $\begin{array}{c}\mathrm{S} \\
(\mathrm{J} / \mathrm{molK})\end{array}$ \\
\hline Bromobenzene & 1 & 317.84 & 4-Methylphenol & 36 & 349.83 \\
\hline Phenol & 2 & 306.46 & $\begin{array}{l}\text { 4-Methyl-3,5- } \\
\text { dinitroaniline }\end{array}$ & 37 & 445.05 \\
\hline 1,2-Dichlorobenzene & 3 & 334.59 & 1,3,5-Trichlorobenzene & 38 & 356.02 \\
\hline 3-Chlorotoluene & 4 & 364.05 & Benzene & 39 & 262.97 \\
\hline 1,3-Dihydroxybenzene & 5 & 323.62 & 2-Nitrotoluene & 40 & 367.64 \\
\hline 3-Hydroxyanisol & 6 & 358.77 & 1,4-Dinitrobenzene & 41 & 388.62 \\
\hline 4-Methyl-3-nitroaniline & 7 & 394.75 & $\begin{array}{l}\text { 2-Methyl-3,6- } \\
\text { dinitroaniline }\end{array}$ & 42 & 441.44 \\
\hline 2,4-Dimethylphenol & 8 & 379.11 & $\begin{array}{l}\text { 2-Methyl-4,6- } \\
\text { dinitrophenol }\end{array}$ & 43 & 441.14 \\
\hline 2,6-Dimethylphenol & 9 & 368.01 & 2,5-Dinitrotoluene & 44 & 425.34 \\
\hline 3-Nitrotoluene & 10 & 380.02 & 1,2-Dinitrobenzene & 45 & 353.05 \\
\hline 2,6-Dinitrotoluene & 11 & 418.03 & 1,4-Dimethoxybenzene & 46 & 415.42 \\
\hline $\begin{array}{l}\text { 4-Methyl-2,6- } \\
\text { dinitroaniline }\end{array}$ & 12 & 434.81 & 2-Methyl-3-nitroaniline & 47 & 393.15 \\
\hline $\begin{array}{l}\text { 5-Methyl-2,6- } \\
\text { dinitroaniline }\end{array}$ & 13 & 435.84 & 2-Methyl-4-nitroaniline & 48 & 390.79 \\
\hline $\begin{array}{l}\text { 5-Methyl-2,4- } \\
\text { dinitroaniline }\end{array}$ & 14 & 452.06 & $\begin{array}{l}\text { 4-Hydroxy-3- } \\
\text { nitroaniline }\end{array}$ & 49 & 384.93 \\
\hline 2,4-Dinitrotoluene & 15 & 424.53 & $\begin{array}{l}\text { 4-Chloro-3- } \\
\text { methylphenol }\end{array}$ & 50 & 364.45 \\
\hline 4-Nitrophenol & 16 & 361.48 & 2,4,6-Tribromophenol & 51 & 420.17 \\
\hline 4-Chlorotoluene & 17 & 361.72 & 2,4,6-Trinitrotoluene & 52 & 374.01 \\
\hline 2,4,6-Trichlorophenol & 18 & 390.64 & $\begin{array}{c}\text { 1,2,4,5- } \\
\text { Tetrachlorobenzene }\end{array}$ & 53 & 385.01 \\
\hline Toluene & 19 & 333.15 & $\begin{array}{l}\text { 3-Methyl-2,4- } \\
\text { dinitroaniline }\end{array}$ & 54 & 439.91 \\
\hline 3-Methyl-6-nitroaniline & 20 & 394.19 & $\begin{array}{l}\text { 2-Methyl-3,5- } \\
\text { dinitroaniline }\end{array}$ & 55 & 449.66 \\
\hline 4-Methyl-2-nitroaniline & 21 & 394.03 & 3,5-Dinitrotoluene & 56 & 449.03 \\
\hline 1,2,4-Trichlorobenzene & 22 & 369.29 & 3,4-Dinitrotoluene & 57 & 436.01 \\
\hline 3,4-Dichlorotoluene & 23 & 389.83 & $\begin{array}{c}1,2,4- \\
\text { Trimethylbenzene }\end{array}$ & 58 & 390.65 \\
\hline 2,4-Dichlorotoluene & 24 & 371.03 & 2,4-Dinitrophenol & 59 & 418.15 \\
\hline
\end{tabular}


HOSSEIN HOSSEINI, FATEMEH SHAFIEI

\begin{tabular}{cccccc}
\hline Compounds & & $\begin{array}{c}\mathrm{S} \\
(\mathrm{J} / \mathrm{molK})\end{array}$ & Compounds & & $\begin{array}{c}\mathrm{S} \\
(\mathrm{J} / \mathrm{molK})\end{array}$ \\
\hline Chlorobenzene & 25 & 312.91 & 3,4-Dimethylphenol & 60 & 366.28 \\
1,3,5-Trinitrobenzene & 26 & 454.21 & 2,4-Dichlorophenol & 61 & 363.99 \\
$\begin{array}{c}\text { 1,2,3,4- } \\
\text { Tetrachlorobenzene }\end{array}$ & 27 & 388.74 & 1,2,3-Trichlorobenzene & 62 & 361.73 \\
$\begin{array}{c}\text { 2,3,4,5,6- } \\
\text { Pentachlorophenol }\end{array}$ & 28 & 440.69 & 2-Methyl-6-nitroaniline & 63 & 385.42 \\
1,3-Dichlorobenzene & 29 & 336.24 & 2-Methyl-5-nitroaniline & 64 & 396.19 \\
2-Chlorophenol & 30 & 335.58 & 1,3-Dinitrobenzene & 65 & 392.01 \\
3-Methylphenol & 31 & 351.15 & 4-Nitrotoluene & 66 & 386.01 \\
2,3-Dinitrotoluene & 32 & 426.83 & 1,2-Dimethylbenzene & 67 & 337.67 \\
1,4-Dimethylbenzene & 33 & 340.90 & 2-Methylphenol & 68 & 337.29 \\
2,3,4,5- & 34 & 416.02 & 1,4-Dichlorobenzene & 69 & 330.48 \\
Tetrachlorophenol & & & & \\
2,3,6-Trinitrotoluene & 35 & 480.08 & & & \\
\hline
\end{tabular}

TOPOLOGICAL INDICES

A large number of topological indices Tis have been defined and used, majority of them being calculated from the various matrices corresponding to molecular graphs. The Adjacency matrix (A) and the Distance matrix (D) of the molecular graph have been most widely used in the definition of topological indices. The most used Tls are presented below.

Randić index (1975), $1 \chi(\mathrm{G})$, was introduced as the connectivity index $[22,23]$ and is defined as (1):

$$
{ }^{1} \chi=\sum_{\text {all edges }}(\mathrm{d}(\mathrm{i}) \mathrm{d}(\mathrm{j}))^{-0.5}
$$

where $d(i)$ and $d(j)$ are the valencies of the vertices $i$ and $j$ defining the edge $(\mathrm{i}, \mathrm{j})$.

Wiener index (1947), W(G), can be defined by (2):

$$
\mathrm{W}(\mathrm{G})=\frac{1}{2} \sum_{i} \sum_{j}[\mathrm{D}(\mathrm{i}, \mathrm{j})]
$$

where $D(i, j)$ is the number of edges on the shortest path joining vertex $i$ and vertex $\mathrm{j}$ (i.e., the topological distance) in the graph [24]. 
Hyper-Wiener index, WW(G), can be defined $[25,26]$ as (3):

$$
\mathrm{WW}(\mathrm{G})=\frac{1}{2}\left(\sum \mathrm{d}(\mathrm{u}, \mathrm{v})+\sum(\mathrm{d}(\mathrm{u}, \mathrm{v}))^{2}\right)
$$

where $d(u, v)$ denotes the distance between the vertices $u$ and $v$ in the graph $G$ and the summations run over all pairs of vertices of $G$.

Randić's original definition (1993) [27] of the hyper-Wiener index is applicable to trees only.

Wiener polarity index (1947), $W_{p}(G)$, of $G$ is the number of unordered pairs of vertices $(u, v)$ of $G$ lying at distance 3 to each other. The Wiener polarity index $[28,29]$ is defined as $(4)$ :

$$
W P(G)=|\{(u, v) \mid d(u, v)=3, u, v \in V\}| \text {. }
$$

Balaban index (1982), J(G) of $G$ was introduced in 1982 [30,31] as one of the less degenerated indices. It calculates the average distance sum connectivity index, according to eq.(5):

$$
\mathrm{J}=\frac{\mathrm{M}}{\mu+1} \sum_{\text {all edges }}\left(\mathrm{D}_{\mathrm{i}} \mathrm{D}_{\mathrm{j}}\right)^{-0.5}
$$

where $M$ is the number of the edges in $G$; and $D_{i}$ is the distance sum from the vertex $i$ to all the other vertices in $G$ (i.e., the sum of all entries in the $i^{\text {th }}$ row of the distance matrix $D$ ).

The cyclomatic number $\mu=\mu(G)$ of a polycyclic graph $G$ is equal to the minimum number of edges that must be removed from $G$ to transform it to the related acyclic graph. For trees, $\mu=0$; for monocycles, $\mu=1$.

Harary number, $H(G)$, was introduced in 1993 [32]. This index is defined by eq. (6)

$$
\mathrm{H}=\frac{1}{2} \sum_{\mathrm{i}=1}^{\mathrm{n}} \sum_{\mathrm{j}=1}^{\mathrm{n}}\left(1 / \mathrm{D}_{\mathrm{i}, \mathrm{j}}\right)
$$

Within this paper, a version of this index is calculated from the inverse of the squared elements of the distance matrix, according to eq.(7):

$$
\mathrm{H}=\frac{1}{2} \sum_{\mathrm{i}}^{n} \sum_{\mathrm{j}}^{n}\left(\mathrm{D}_{\mathrm{ij}}\right)^{-2}
$$

where $D_{i, j}$ is the entry in the distance matrix $D$. 
Szeged index, $\mathrm{Sz}(\mathrm{G})$, was introduced by Gutman $[33,34]$ as $(8)$ :

$$
\mathrm{Sz}_{\mathrm{v}}(\mathrm{G})=\sum_{\mathrm{e}} \mathrm{n}_{\mathrm{u}}(\mathrm{e} \mid \mathrm{G}) \cdot \mathrm{n}_{\mathrm{v}}(\mathrm{e} \mid \mathrm{G})
$$

$n_{v} \mid=n_{v}(e \mid G)$ is the number of vertices of $G$ whose distance to the vertex $\mathrm{v}$ is smaller than the distance to the vertex $\mathrm{u}$. Note that vertices equidistant to $\mathrm{u}$ and $\mathrm{v}$ are not counted.

All the used topological indices were calculated in hydrogen suppressed graphs. The descriptors were calculated with Chemicalize program [35]. Seven topological indices tested in the present study are listed in Table 2.

\section{STATISTICAL ANALYSIS}

Structure-Property models (MLR models) are generated using the multi linear regression procedure of SPSS, version 16. The entropy (S, J/mol $\mathrm{K}$ ) is used as the dependent variable and $1 \chi, \mathrm{J}, \mathrm{H}, \mathrm{Sz}, \mathrm{WW}, \mathrm{W}_{\mathrm{p}}$ and $\mathrm{W}$ indices are used as the independent variables. The models are assessed with $r$ value (correlation coefficient), the $r^{2}$ (coefficient of determination), the $r^{2}$ - adjusted, the $s$ value (root of the mean square of errors), the $F$ value (Fischer statistic), the D value (Durbin-Watson) and the Sig (significant).

\section{RESULTS AND DISCUSSION}

Several linear QSPR models involving three to seven descriptors were established and the strongest multivariable correlations were identified by the backward method, with significant at the 0.05 level and regression analysis of the SPSS program. In the first of this study we drown scattering plots of $S$ versus the seven topological indices $(1 \chi, J, H, S z, W W, W p, W)$. Some of these plots are given in Figs. 1 to 3 , respectively.

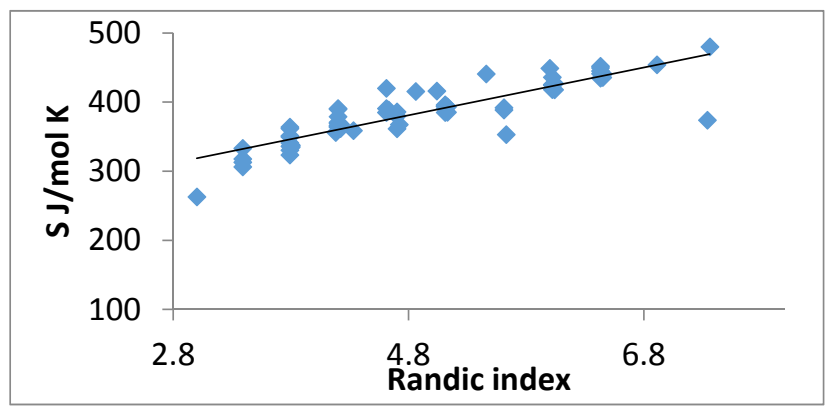

Figure 1. Plot of the Randić index $(1 \chi)$ versus entropy of 69 benzene derivatives. 
ENTROPY PREDICTION OF BENZENE DERIVATIVES USING TOPOLOGICAL INDICES

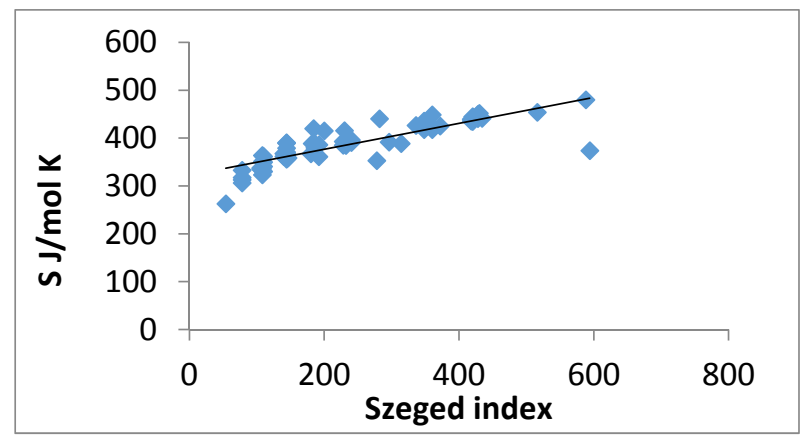

Figure 2. Plot of the Szeged index (Sz) versus entropy of 69 benzene derivatives.

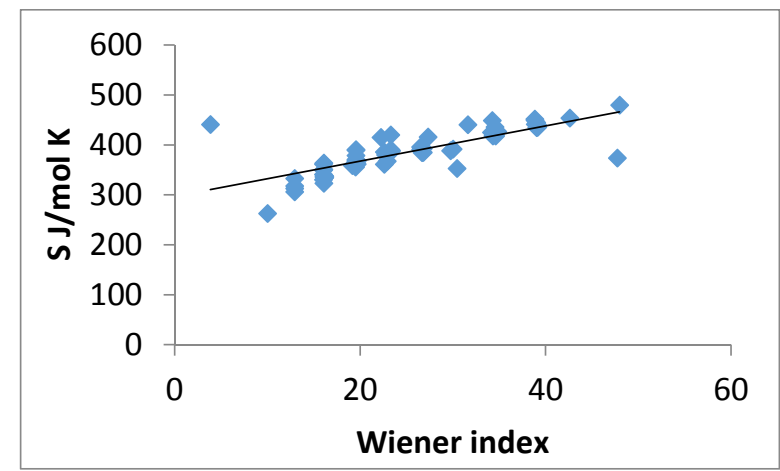

Figure 3. Plot of the Wiener (W) versus entropy of 69 benzene derivatives.

Table 2. Benzene derivatives and their topological indices, used in present study.

\begin{tabular}{cccccccc}
\hline $\mathrm{A}$ & ${ }^{1} \chi$ & $\mathrm{J}$ & $\mathrm{H}$ & $\mathrm{W}$ & $\mathrm{WW}$ & $\mathrm{W}_{\mathrm{p}}$ & $\mathrm{Sz}$ \\
\hline 1 & 3.39 & 1.82 & 12.92 & 42 & 71 & 5 & 78 \\
2 & 3.39 & 1.82 & 12.92 & 42 & 71 & 5 & 78 \\
3 & 3.80 & 2.28 & 16.17 & 60 & 106 & 8 & 106 \\
4 & 3.79 & 2.23 & 16.08 & 61 & 110 & 7 & 108 \\
5 & 3.79 & 2.23 & 16.08 & 61 & 110 & 7 & 108 \\
6 & 4.33 & 1.98 & 19.15 & 88 & 176 & 9 & 146 \\
7 & 5.11 & 2.25 & 26.67 & 148 & 315 & 14 & 232 \\
8 & 4.20 & 2.09 & 19.53 & 84 & 160 & 10 & 144 \\
9 & 4.22 & 2.15 & 19.67 & 82 & 151 & 11 & 140 \\
10 & 4.70 & 2.32 & 22.73 & 117 & 245 & 11 & 186 \\
11 & 6.04 & 2.40 & 34.60 & 234 & 545 & 19 & 348 \\
12 & 6.43 & 2.70 & 39.02 & 282 & 669 & 21 & 420 \\
\hline
\end{tabular}


HOSSEIN HOSSEINI, FATEMEH SHAFIEI

\begin{tabular}{|c|c|c|c|c|c|c|c|}
\hline$A$ & ${ }^{1} \chi$ & $\mathrm{J}$ & $\mathrm{H}$ & W & WW & $W_{p}$ & $\mathrm{Sz}$ \\
\hline 13 & 6.45 & 2.72 & 39.13 & 281 & 667 & 22 & 418 \\
\hline 14 & 6.43 & 2.65 & 38.83 & 287 & 698 & 21 & 430 \\
\hline 15 & 6.02 & 2.33 & 34.30 & 240 & 576 & 18 & 360 \\
\hline 16 & 4.70 & 2.26 & 22.60 & 120 & 262 & 11 & 192 \\
\hline 17 & 3.79 & 2.19 & 16.03 & 62 & 115 & 7 & 110 \\
\hline 18 & 4.61 & 2.49 & 23.28 & 110 & 215 & 13 & 184 \\
\hline 19 & 3.39 & 1.82 & 12.92 & 42 & 71 & 5 & 78 \\
\hline 20 & 5.11 & 2.22 & 26.60 & 150 & 327 & 14 & 236 \\
\hline 21 & 5.11 & 2.25 & 26.67 & 148 & 315 & 14 & 232 \\
\hline 22 & 4.20 & 2.09 & 19.53 & 84 & 160 & 10 & 144 \\
\hline 23 & 4.20 & 2.09 & 19.53 & 84 & 160 & 10 & 144 \\
\hline 24 & 4.20 & 2.09 & 19.53 & 84 & 160 & 10 & 144 \\
\hline 25 & 3.39 & 1.82 & 12.92 & 42 & 71 & 5 & 78 \\
\hline 26 & 6.91 & 2.46 & 42.60 & 354 & 906 & 21 & 516 \\
\hline 27 & 4.63 & 2.52 & 23.37 & 109 & 211 & 14 & 182 \\
\hline 28 & 5.46 & 2.76 & 31.60 & 174 & 357 & 21 & 282 \\
\hline 29 & 3.79 & 2.23 & 16.08 & 61 & 110 & 7 & 108 \\
\hline 30 & 3.80 & 2.28 & 16.17 & 60 & 106 & 8 & 106 \\
\hline 31 & 3.79 & 2.23 & 16.08 & 61 & 110 & 7 & 108 \\
\hline 32 & 6.04 & 2.47 & 34.83 & 228 & 511 & 19 & 336 \\
\hline 33 & 3.79 & 2.19 & 16.03 & 62 & 115 & 7 & 110 \\
\hline 34 & 5.04 & 2.39 & 27.32 & 140 & 281 & 17 & 230 \\
\hline 35 & 7.36 & 2.83 & 47.97 & 405 & 1036 & 26 & 588 \\
\hline 36 & 3.79 & 2.19 & 16.03 & 62 & 115 & 7 & 110 \\
\hline 37 & 6.43 & 2.70 & 39.02 & 282 & 669 & 21 & 420 \\
\hline 38 & 4.18 & 2.08 & 19.50 & 84 & 159 & 9 & 144 \\
\hline 39 & 3.00 & 2.00 & 10.00 & 27 & 42 & 3 & 54 \\
\hline 40 & 4.72 & 2.40 & 22.90 & 114 & 231 & 12 & 180 \\
\hline 41 & 5.61 & 2.30 & 29.74 & 206 & 521 & 15 & 314 \\
\hline 42 & 6.45 & 2.64 & 38.87 & 289 & 717 & 22 & 434 \\
\hline 43 & 6.43 & 2.66 & 3.85 & 286 & 691 & 21 & 428 \\
\hline 44 & 6.02 & 2.28 & 34.14 & 246 & 616 & 18 & 372 \\
\hline 45 & 5.63 & 2.54 & 30.43 & 188 & 416 & 16 & 278 \\
\hline 46 & 4.86 & 2.17 & 22.24 & 125 & 287 & 11 & 200 \\
\hline 47 & 5.13 & 2.28 & 26.80 & 146 & 306 & 15 & 228 \\
\hline 48 & 5.11 & 2.18 & 26.50 & 152 & 337 & 14 & 240 \\
\hline 49 & 5.11 & 2.25 & 26.67 & 148 & 315 & 14 & 232 \\
\hline 50 & 4.20 & 2.09 & 19.53 & 84 & 160 & 10 & 144 \\
\hline 51 & 4.61 & 2.49 & 23.28 & 110 & 215 & 13 & 184 \\
\hline 52 & 7.34 & 2.80 & 47.72 & 408 & 1044 & 25 & 594 \\
\hline 53 & 4.61 & 2.46 & 23.23 & 111 & 220 & 13 & 186 \\
\hline 54 & 6.45 & 2.72 & 39.13 & 281 & 667 & 22 & 418 \\
\hline 55 & 6.43 & 2.66 & 38.85 & 286 & 691 & 21 & 428 \\
\hline
\end{tabular}




\begin{tabular}{cccccccc}
\hline $\mathrm{A}$ & ${ }^{1} \chi$ & $\mathrm{J}$ & $\mathrm{H}$ & $\mathrm{W}$ & $\mathrm{WW}$ & $\mathrm{W}_{\mathrm{p}}$ & $\mathrm{Sz}$ \\
\hline 56 & 6.00 & 2.33 & 34.23 & 240 & 573 & 17 & 360 \\
57 & 6.02 & 2.40 & 34.53 & 234 & 542 & 18 & 348 \\
58 & 4.20 & 2.09 & 19.53 & 84 & 160 & 10 & 144 \\
59 & 6.02 & 2.33 & 34.3 & 240 & 576 & 18 & 360 \\
60 & 4.20 & 2.09 & 19.53 & 84 & 160 & 10 & 144 \\
61 & 4.20 & 2.09 & 19.53 & 84 & 160 & 10 & 144 \\
62 & 4.22 & 2.15 & 19.67 & 82 & 151 & 11 & 140 \\
63 & 5.13 & 2.28 & 26.8 & 146 & 306 & 15 & 228 \\
64 & 5.11 & 2.18 & 26.5 & 152 & 337 & 14 & 240 \\
65 & 5.61 & 2.40 & 30.02 & 197 & 464 & 15 & 296 \\
66 & 4.70 & 2.26 & 22.6 & 120 & 262 & 11 & 192 \\
67 & 3.80 & 2.28 & 16.17 & 60 & 106 & 8 & 106 \\
68 & 3.80 & 2.28 & 16.17 & 60 & 106 & 8 & 106 \\
69 & 3.79 & 2.19 & 16.03 & 62 & 115 & 7 & 110 \\
\hline
\end{tabular}

Distribution of the dependent variable against the independent variable for 69 chemicals was employed in developing quantitative structure- properties relationships. For obtaining appropriate QSPR models we used maximum $\mathrm{R}^{2}$ method and followed backward regression analysis. The predictive ability of the model is discussed on the basis of predictive correlation coefficient.

\section{QSPR MODELS FOR ENTROPY (S)}

Initial regression analysis indicated that combination of seven topological indices plays a dominating role in modeling the entropy. Table 3 provides the regression parameters and quality of correlation of the proposed models for entropy of 69 benzene derivatives.

Table 3. Statistics of models calculated with SPSS software

\begin{tabular}{|c|c|c|c|c|c|c|c|}
\hline \multicolumn{2}{|c|}{ Model Independent variables } & $r$ & $r^{2}$ & $r_{a d j}^{2}$ & s & $\mathrm{F}$ & Sig \\
\hline 1 & Sz, J, H, Wp, 1X, WW, W & 0.929 & 0.864 & 0.848 & 16.691 & 55.222 & 0.000 \\
\hline 2 & Sz, J, Wp, 1X, WW, W & 0.929 & 0.864 & 0.850 & 16.559 & 65.454 & 0.000 \\
\hline 3 & Sz, Wp, 1X, WW, W & 0.929 & 0.862 & 0.851 & 16.510 & 78.879 & 0.000 \\
\hline 4 & Sz, 1x, Wp, W & 0.927 & 0.860 & 0.851 & 16.518 & 98.244 & 0.000 \\
\hline 5 & $S z, 1 X, W$ & 0.927 & 0.859 & 0.853 & 16.430 & 132.299 & 0.000 \\
\hline
\end{tabular}


The best linear model contains three topological descriptors, namely, Randić $(1 \chi)$, Wiener $(\mathrm{W})$ and Szeged (Sz) indices.

The regression parameters of the best three descriptor correlation model are gathered in equation 9 .

$$
\begin{aligned}
& S=70.258+59.966 X+2.748 S z-4.163 W \\
& r=0.927 ; r^{2}=0.859 ; r_{a d j}^{2}=0.859 ; \\
& S=16.430 ; D=2.033 ; \\
& F=132.299 ; \text { mean square }=269.936
\end{aligned}
$$

This model produced a standard error of $16.430 \mathrm{~J} \mathrm{~mol}^{-1} \mathrm{~K}^{-1}$, a correlation coefficient of 0.927, and the adjusted correlation coefficient (adjusted r-squared) was calculated as 0.859 .

The result is therefore very satisfactory. Figure 4 shows the linear correlation between the observed and the predicted entropy values obtained using equation (9).

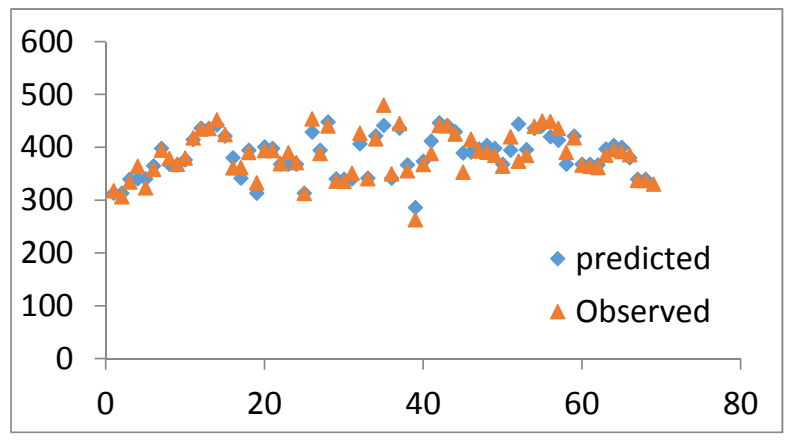

Figure 4. Comparison between the predicted and observed entropy by MLR method (cf. eq. 9)

\section{The DURBIN-WATSON STATISTIC}

To verify and validate the regression models, we will focus on the Durbin-Watson (D) statistic, unstandardized predicted and residual values.

The Durbin-Watson statistic ranges in value from 0 to 4 . A value near 2 indicates non-autocorrelation; a value toward 0 indicates positive autocorrelation; a value toward 4 indicates negative autocorrelation. Therefore the value of Durbin-Watson statistic is close to 2 if the errors are uncorrelated. In our model, the value of Durbin-Watson statistic for model 5 is close to 2 (See Eq. 9) hence the errors are uncorrelated. 


\section{RESIDUAL VALUES}

The residual values of entropy expressed by equation (9) are shown in Table 4. The residual values show a fairly random pattern (see Figure 5). This random pattern indicates that a linear model provides a decent fit to the data.

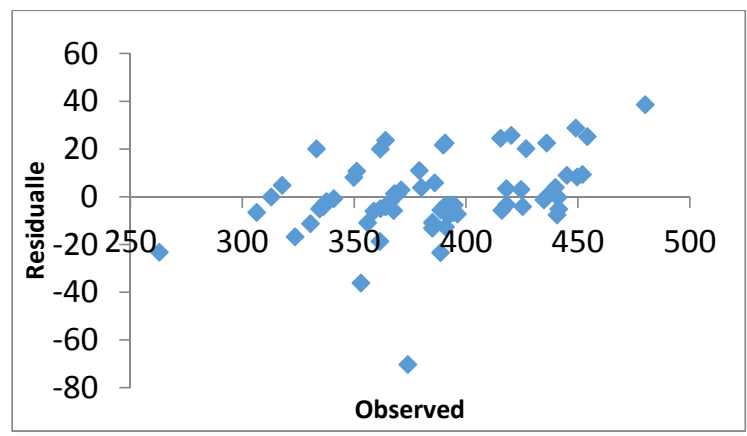

Figure 5. Plot of residuals against observed values of benzene derivatives entropy (S).

Table 4. Entropy (S) data of benzene derivatives.

\begin{tabular}{clll|llll}
\hline No. & $\begin{array}{l}\text { Observed } \\
\text { S(J/molK) }\end{array}$ & $\begin{array}{l}\text { Predicted } \\
\text { S(J/molK) }\end{array}$ & Residual & No. & $\begin{array}{l}\text { Observed } \\
\text { S(J/molK) }\end{array}$ & $\begin{array}{l}\text { Predicted } \\
\text { S(J/molK) }\end{array}$ & Residual \\
\hline 1 & 317.835 & 313.051 & 4.784 & 36 & 349.828 & 341.718 & 8.110 \\
2 & 306.457 & 313.051 & -6.594 & 37 & 445.053 & 436.089 & 8.964 \\
3 & 334.588 & 339.651 & -5.063 & 38 & 356.019 & 366.955 & -10.936 \\
4 & 364.048 & 340.385 & 23.663 & 39 & 262.968 & 286.154 & -23.186 \\
5 & 323.616 & 340.385 & -16.769 & 40 & 367.639 & 373.379 & -5.740 \\
6 & 358.773 & 364.794 & -6.021 & 41 & 388.619 & 412.003 & -23.384 \\
7 & 394.751 & 398.127 & -3.376 & 42 & 441.441 & 446.622 & -5.181 \\
8 & 379.109 & 368.154 & 10.955 & 43 & 441.136 & 441.422 & -0.286 \\
9 & 368.007 & 366.687 & 1.320 & 44 & 425.335 & 429.461 & -4.126 \\
10 & 380.017 & 376.180 & 3.837 & 45 & 353.047 & 389.203 & -36.156 \\
11 & 418.029 & 414.661 & 3.368 & 46 & 415.421 & 390.944 & 24.477 \\
12 & 434.807 & 436.089 & -1.282 & 47 & 393.149 & 396.660 & -3.511 \\
13 & 435.840 & 435.955 & -0.115 & 48 & 390.792 & 403.460 & -12.668 \\
14 & 452.059 & 442.756 & 9.303 & 49 & 384.928 & 398.127 & -13.199 \\
15 & 424.529 & 421.461 & 3.068 & 50 & 364.454 & 368.154 & -3.700 \\
16 & 361.482 & 380.180 & -18.698 & 51 & 420.165 & 394.428 & 25.737 \\
17 & 361.720 & 341.718 & 20.002 & 52 & 374.009 & 444.296 & -70.287 \\
18 & 390.637 & 394.428 & -3.791 & 53 & 385.007 & 395.761 & -10.754
\end{tabular}


HOSSEIN HOSSEINI, FATEMEH SHAFIEI

\begin{tabular}{llll|llll}
\hline No. & $\begin{array}{l}\text { Observed } \\
\text { S(J/molK) }\end{array}$ & $\begin{array}{l}\text { Predicted } \\
\text { S(J/molK) }\end{array}$ & Residual & No. & $\begin{array}{l}\text { Observed } \\
\text { S(J/molK) })\end{array}$ & $\begin{array}{l}\text { Predicted } \\
\text { S(J/molK })\end{array}$ & Residual \\
\hline 19 & 333.154 & 313.051 & 20.103 & 54 & 439.912 & 435.955 & 3.957 \\
20 & 394.186 & 400.794 & -6.608 & 55 & 449.659 & 441.422 & 8.237 \\
21 & 394.032 & 398.127 & -4.095 & 56 & 449.028 & 420.262 & 28.766 \\
22 & 369.290 & 368.154 & 1.136 & 57 & 436.007 & 413.461 & 22.546 \\
23 & 389.827 & 368.154 & 21.673 & 58 & 390.650 & 368.154 & 22.496 \\
24 & 371.033 & 368.154 & 2.879 & 59 & 418.150 & 421.461 & -3.311 \\
25 & 312.911 & 313.051 & -0.140 & 60 & 366.281 & 368.154 & -1.873 \\
26 & 454.207 & 428.958 & 25.249 & 61 & 363.994 & 368.154 & -4.160 \\
27 & 388.735 & 394.294 & -5.559 & 62 & 361.725 & 366.687 & -4.962 \\
28 & 440.693 & 448.284 & -7.591 & 63 & 385.417 & 396.660 & -11.243 \\
29 & 336.239 & 340.385 & -4.146 & 64 & 396.188 & 403.460 & -7.272 \\
30 & 335.579 & 339.651 & -4.072 & 65 & 392.008 & 400.003 & -7.995 \\
31 & 351.149 & 340.385 & 10.764 & 66 & 386.006 & 380.180 & 5.826 \\
32 & 426.832 & 406.661 & 20.171 & 67 & 337.673 & 339.651 & -1.978 \\
33 & 340.904 & 341.718 & -0.814 & 68 & 337.288 & 339.651 & -2.363 \\
34 & 416.018 & 421.738 & -5.720 & 69 & 330.475 & 341.718 & -11.243 \\
35 & 480.077 & 441.495 & 38.582 & & & & \\
\hline
\end{tabular}

\section{CONCLUSIONS}

In this work, QSPR models for the prediction of entropy for a training set of benzene derivatives using MLR based on topological descriptors calculated from molecular structure have been developed. MLR model is proved to be a useful tool in the prediction of entropy. The aforementioned results and discussion lead us to conclude that combining the three descriptors

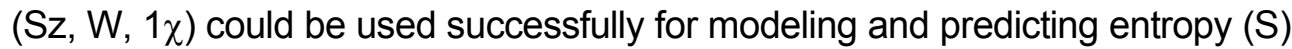
of compounds. This model contains fewer topological descriptors, maximum of Fischer statistic value $(F)$ and minimum root of the mean square of errors(s).

\section{REFERENCES}

1. X.J. Yao, B. Fan, J.P. Doucet, A. Panaye, M. Liu, R. Zhang, X. Zhang and Z. $\mathrm{Hu}, \mathrm{QSAR}$ \& Combinatorial Science, 2003, 22, 29.

2. A.A. Taherpour, F. Shafiei, Journal of Molecular Structure: THEOCHEM, 2005, 726, 183.

3. F. Shafiei, Iranian Journal of Mathematical Chemistry, 2015, 6, 15.

4. P.R. Duchowicz, E.A. Castro, F.M. Fernández and A.N. Pankratov, Journal of the Argentine Chemical Society, 2006, 94, 31. 
5. Z. Lin, J. Xu, X. Zheng and Z. Li, Acta Physico-Chimica Sinica, 2000, 16,153.

6. F. Gharagheizi, M.R. Samiee Gohar and M. Ghotbi Vayeghan, Journal of Thermal Analysis and Calorimetry, 2012, 109, 501.

7. E. Estrada, O. Ivanciuc, I.Gutman, A.Gutierrez and L. Rodríguez, New Journal of Chemistry, 1998, 22, 819.

8. H. Hosoya, M. Gotoh, M. Murakami and S. Ikeda, Journal of Chemical Information and Computer Sciences, 1999, 39, 192.

9. Y.P. Du, Y.Z. Liang, B.Y. Li and C.J. Xu, Journal of Chemical Information and Computer Sciences, 2002,42,1128.

10. D. Plavsic, S. Nikolic, N. Trinajstic, and Z. Mihalic, Journal of Mathematical Chemistry, 1993, 12, 235.

11. A.T. Balaban, Journal of Molecular Structure: THEOCHEM, 1998,165, 243.

12. P.R. Duchowicz, E.A. Castro, F.M. Fernández and A.N. Pankratov, Journal of the Argentine Chemical Society, 2006, 94, 31.

13. O. Ivanciuc, Revue Roumaine de Chimie, 1995,40,1093.

14. J. Taskinen and J. Yliruusi. Advanced Drug Delivery Reviews, 2003, 55, 1163.

15. L.H. Hall and C.T. Story, SAR and QSAR in Environmental Research, 1997, 6,139 .

16. Li. Qianfeng, Chen. Xingguo and $\mathrm{Hu}$. Zhide, Chemometrics and Intelligent Laboratory Systems, 2004, 72, 93.

17. E.S. Domalski and E.D. Hearing, Journal of Physical and Chemical Reference Data, 1988, 17, 1637.

18. J.S. Chickos, C.M. Braton, D.G. Hesse and J.F. Liebman, The Journal of Organic Chemistry, 1991, 56, 927.

19. J.S. Chickos, W.E. Acree, Jr. and J.F. Liebman, Journal of Physical and Chemical Reference Data, 1999, 28, 1535.

20. Mu. Lailong, Feng. Changjun, MATCH Communications in Mathematical and in Computer Chemistry, 2007, 111.

21. Mu. Lailong, He. Hongmei, Industrial \& Engineering Chemistry Research, 2011, 50, 8764.

22. M. Randić, Journal of Mathematical Chemistry, 1991, 7, 155.

23. M. Randic', Journal of the American Chemical Society, 1975, 97, 6609.

24. M. Randic', Acta Chimica Slovenica, 2002, 49, 483.

25. B. Zhou, I. Gutman, Chemical Physics Letters, 2004, 394, 93.

26. D.J. Klein, W. Yan, Y.N. Yeh, International Journal of Quantum Chemistry, 2006, 106, 1756.

27. D. J.Klein, I. Lukovits, I. Gutman, Journal of Chemical Information and Computer Sciences, 1995, 35, 50.

28. M. Liu1, B. LiuOn, MATCH Communications in Mathematical and in Computer Chemistry, 2011, 66,293.

29. H. Deng, H. Xiao, F. Tang, MATCH Communications in Mathematical and in Computer Chemistry, 2010, 63,257.

30. A.T. Balaban, Chemical Physics Letters, 1982, 89, 399.

31. L. Blaha, J. Damborsky, M. Nemec, Chemosphere, 1998, 36,1345. 
32. C.K. Das, B. Zhou, N. Trinajstic, Journal of Mathematical Chemistry, 2009, 1369.

33. I. Gutman, S. Klavzar, Journal of Chemical Information and Computer Sciences, 1995, 35, 1011.

34. P.V. Khadikar, N.V. Deshpande, P.P. Dobrynin, Journal of Chemical Information and Computer Sciences, 1995, 35, 547.

35. Web search engine developed by ChemAxon; software available at $h t t p: / / w w w$. Chemicalize. Org. 